lesions of the same nature as described above. However, the lesions did not appear until about Io days after exposure. The young were born 2 days after treatment and appeared normal. After about a week they began to fail considerably, hemorrhagic areas appeared along the mid-dorsal line, especially in the head region and death followed. The hemorrhages in these animals were mainly along the meningeal sinuses (figures shown), in some cases frontal and occipital hemorrhages were just beginning, in others they extended considerably over the cerebral hemispheres. Additional lesions on the dorsal side of the thorax were found.

The interval of ro days after treatment strictly corresponds to the time at which a primary skin erythema develops in radium treated patients. Again it seems as if the endothelial walls had been injured at the time of exposure and gradually gave way to the blood pressure.

In the course of the experiments, we also found numerous hemorrhagic areas in the uteri and especially in the ovaries (figures shown). Congestion of the uterine vessels always was pronounced.

While in experiments on adult animals reported by Bagg before, the injection of radium emanation led to considerable injuries in the internal organs, in our experiments the weaker doses did not produce any macroscopically visible effects on the maternal tissues. However, the embryonic differentiating tissues were easily affected. This fact might be of some biological significance, when one remembers that radium rays have a decided effect on fast growing tumor and cancer tissues.

\title{
99 (I559)
}

The influence of phenylcinchoninic acid and its methyl derivative on the uric acid and urea content of the blood.

By V. C. Myers, J. A. Killian and G. E. Simpson.

[From the Laboratory of Pathological Chemistry, New York PostGraduate Medical School and Hospital.]

It has been recognized now for some time that the administration of salicylates and phenylcinchoninic acid (cinchophen) 
resulted in an increased excretion of uric acid in the urine. Quite recently it has been shown by Folin and Lyman, ${ }^{1}$ and Fine and Chace, ${ }^{2}$ in particular, that this action was accompanied by a marked drop in the uric acid content of the blood, and later the same was shown to be true of salicylates by Fine and Chace, ${ }^{3}$ and Denis. ${ }^{4}$ It has been assumed that these drugs induce an increased output of uric acid by endowing the renal cells with an increased power for eliminating uric acid. Fine and $\mathrm{Chace}^{5}$ have pointed out that, in the last stages of interstitial nephritis cinchophen has little influence on the excretion of the uric acid, indicating that the renal cells can no longer be stimulated to increased activity.

Influence of Phenylcinchoninic Acid and its Methyl Derivative on the URic and UREa Content of the Blood.

\begin{tabular}{c|c|c|c|c}
\hline Case. & Date r920. & $\begin{array}{c}\text { Uric Acid } \\
\text { Mg. to roo C.c. }\end{array}$ & $\begin{array}{c}\text { Urea N } \\
\text { Mg. to roo C.c. }\end{array}$ & $\begin{array}{c}\text { Creatinine } \\
\text { Mg. to roo C.c. }\end{array}$ \\
\cline { 1 - 2 } I. M.G........ & $3 / 26$ & 6.0 & 29 & 1.5 \\
& $3 / 28$ & 5.2 & 29 & 2.4 \\
& $3 / 31$ & trace & 16 & 2.0 \\
& $4 / 5$ & 3.0 & 24 & 2.2 \\
& $4 / 12$ & 3.5 & 18 & 3.0 \\
& $4 / 13$ & 3.9 & 15 & 2.4 \\
& $3 / 16$ & 2.8 & 26 & 2.6 \\
& $3 / 18$ & 2.8 & 22 & 2.6 \\
& $3 / 22$ & trace & 13 & 2.7 \\
& $3 / 25$ & 2.6 & 20 & 2.4 \\
& $3 / 29$ & 2.6 & 19 & 2.2 \\
& $4 / 9$ & 2.8 & 16 & 2.4 \\
& $4 / 12$ & 0.7 & 13 & 2.6 \\
& $4 / 15$ & 2.0 & 17 & 2.4 \\
\hline
\end{tabular}

Case $\mathrm{r}$, male, aged 58; clinical diagnosis, chronic interstitial nephritis, arteriosclerosis; 50 grains tolysin daily $3 / 28$ to $4 / 3$.

Case 2, female, aged 53; clinical diagnosis, neurasthenia, visceroptosis; vegetable diet; 50 grains tolysin daily 3/19-22; 50 grains cinchophen daily 4/9-12.

We have been endeavoring to obtain further light on the mechanism of the action of these drugs by experiments upon both man and animals. Setting aside cases of advanced interstitial nephritis where the action of cinchophen is comparatively slight, we have been struck by the fact that this drug and its methyl

1 Folin and Lyman, Jour. Pharmacol. and Exper. Therap., 1912-13, IV, 539.

2 Fine and Chace, Jour. Pharmacol. and Exper. Therap., I9r4, VI, 2 I9.

- Fine and Chace, Jour. Biol. Chem., I9I5, XXI, 37 r.

- Denis, Jour. Pharmacol. and Exper. Therap., I9I5. VII, 255, 60I.

Fine and Chace, Arch. Int. Med., r9r5, XVI, 401. 
derivative show quite different ability to lower the blood uric acid in different individuals, the action being very pronounced in some cases and comparatively slight in others.

In their experiments Folin and Lyman noted the interesting fact (in two cases) that cinchophen not only brings about a dimunition of the uric acid in the blood but also seems to lead to a dimunition of the nonprotein nitrogen and urea whenever these are present in the blood in unusual amounts. Unfortunately these two experiments were not followed by a control after period.

Data are given in the table above on two cases in which we believe there is unmistakable evidence of a drop in the blood urea as well as in the uric acid. It will be noted that the action on the uric acid was very pronounced in both cases, the first case having a high and the second a normal initial uric acid.

$$
100(1560)
$$

The purification and concentration of antigens by new methods of adsorption.

\section{By Augustus B. Wadsworth and Frank Maltaner.}

[From the Division of Laboratories and Research, New York State Department of Health, Albany.]

The results of recent studies of complement fixation in tuberculosis suggest that the test might be of considerable diagnostic value if satisfactory antigens could be prepared.

Three strains of tubercle bacilli were selected: one a virulent, another a non-virulent, human strain and a third bovine strain. Immune serum sufficient for titration with all the antigens was obtained from inoculated horses.

The antigens were prepared from cultures by various methods of fractioning and extraction similar to those used by other observers. The culture filtrates were so anticomplementary that they could rarely be used. The glycerine and distilled water extracts gave the most active antigens. These active antigens and also the culture filtrates for comparison were selected for further study by methods of adsorption. 